\title{
Designing a Knowledge Strategy Model for Iranian Public Organizations: A Study on Electricity Industry
}

\author{
Abolhasan Faghihi ${ }^{1}$,Gholamreza Memarzadeh ${ }^{2}$,Saeed Safari ${ }^{3}$, \\ Hojjat Taheri Goodarzi ${ }^{4}$ \\ 1. Department of Public Management, Science and Research Branch, ISLAMIC AZAD UNIVERSITY,TEHRAN, \\ IRAN \\ 2. Department of Public Management, Science and Research Branch, ISLAMIC AZAD UNIVERSITY,TEHRAN, \\ IRAN \\ 3. Department of Management, SHAHED UNIVERSITY,TEHRAN, IRAN \\ 4. PHD Graduate of Public Management, Science and Research Branch, ISLAMIC AZAD \\ UNIVERSITY,TEHRAN, IRAN (Corresponding Author)
}

\begin{abstract}
The present paper raises these questions that how is the state of knowledge strategy in Iran's public organizations now (Electricity Industry) and how should be the state of knowledge strategy in Iran's public organizations (Electricity Industry) until horizon 2025 and also what is the combination of optimal knowledge strategies to fill the knowledge gaps in the Iran's public organizations (Electricity Industry). The purpose of these questions is to identify and explain knowledge strategies and also make strategic change in the current knowledge management in public organizations in order to fill the gap between the perceived situation of perspective horizon and current situation of knowledge management proportional to prevailing conditions in public organizations. In order to determine the knowledge strategies in public organizations, at first the main assumptions of knowledge strategy design in both areas of internal environment and external environment were considered and by using Fuzzy Delphi method, opportunities, threats, strengths and weaknesses of knowledge were identified and then knowledge strategies were identified by using the experts opinion and prioritized by technique of Network Analysis. Statistical population of this study is public organizations in Electricity Industry that 137 samples were selected randomly and by using questionnaires with help of Gap Analysis, the difference between current and desired situation was identified. According to the Gap Analysis that is done in four axes of knowledge strategy, some actions are proposed in the form of Forty-nine solutions to improve the current situation and reduce the gap.
\end{abstract}

Keywords: knowledge strategy, knowledge source, Knowledge base, knowledge accumulation, knowledge flow, Gap Analysis,

\section{Introduction}

We live in a world that is undergoing a rapid and inevitable change because of the phenomena of globalization (Bolisani, Scarso, 2009). To survive, and to go on powerfully in the presence of the variable working conditions, many institutes in the private sector have come to use modern management tools, techniques and methods (Haider, 2009 ،10). Evidences show that there is an increasing tendency in the public organizations to make use of knowledge strategies and the governments have come to understand the necessity and importance of knowledge in policy making and service giving. Knowledge management has also come to be a part of the government plants (Cong \& Pandya, 2003.23).In other words; Knowledge management is of a great importance in dealing with the economic challenges of the $21^{\text {th }}$ century. Those challenges can be pondered from these perspectives:

1: Knowledge has turned to be a determining factor for competition in public sector. Policy making and service giving are the two main activities of the governments and in a knowledge base economy, the governments in both two fields, have faced competition on national as well as the international level (Barquin, 2004,24).

2: The merchandise produced and the services given by the private sector is in direct competition with the merchandise and the services of the public sector. When the private sector provides the order on the customers' demand and according to his taste, the customers will demand the same thing from the public sector (Smith \& McKeen, 2003).

3: The retirement of the government personnel or their turnover to other sectors puts new challenges in the way of accumulating the knowledge, keeping the organization memory and consequently the training of new personnel ( Jussilainen, 2005,22). According to the spring 1389 report from the office of Community Statistics, Labor Force and Head counting of Iran's Statistics Center the pyramid represents the age increase of the civil servants and the fact that $29 \%$ of them will be retired in the next years. Relatively, based on a report by the database of Assistant of the development of the Human Resource Management of the Oil Ministry, only about 
12 thousands of the managers in this ministry are going to be retired. Therefore, the public organizations need to do initiative works in order to enhance the knowledge level of their personnel and their chief managers, unless their general service giving system will fall into problems.

In National Service Management Rule the Knowledge management has also been emphasized. In this rule, the government has been defined by words like: analyst, enterpriser and small. According to, National Service Management Rule, the government and public organizations' structures must be limited, rule-based and flexible. Governmental managers should also be enterpriser, creative and pioneer in the realms of science, advancement and change.

Despite the fact that the present day organizations are fully aware of the fact that for their success in the realm of competition must come up with the strategic management of the resources and knowledge properties. To this aim, different programs and management projects are planned and ready to run (Holsapple \& Jones, 2006, 24). But, the main emphasis of these programs and activities is on the development of the capabilities of the IT for protecting, collecting, storing, recycling and distributing documented knowledge among organizations. Although, investment on the required sub-structures for enabling the organizations to generate and apply science would be fruitful, it would by no means guarantee that the organization has done the best investment for optimum management of knowledge resources or the organization manages the true knowledge in the best way (Zack, 2002). Thus, it can be claimed that for the governmental managers who are going to operate systems and tools in their due organization, determining the knowledge strategies is of respectable position, in the way that by the absence of it, the probability of failure of these activities would increase since we cannot decide on the processes and the way of managing an organization without taking care of the quantity, type and the quality of the required knowledge as well as the way of grasping it. Hence, determining the knowledge strategy in an organization is the required condition for successful operation of the management processes (Kasten, 2007).

The evidences show that in many of the Iranian public organizations, for example the Electricity Ministry, Oil Ministry, etc, benefiting from knowledge, expertness and experience of a large number of experts in different fields, various projects with different topic are going on in the way that their completion will produce a great body of knowledge. A part of this knowledge will be recorded in the form of document and evidence, report, software, instruction, etc. The remaining part which is impalpable is in the form of experience, relation, skill, insight, etc. They are latent and there is less probability in utilizing or transforming it. Thus, regarding the basic role of the government in the society, the knowledge strategies are necessary for having knowledge based government and organizations. In other words, since the lack of knowledge based strategy will result in fragile condition of organization's intellectual properties, in long time and by the increasing of the role of knowledge in organizational and inter-organizational equations (Choi, et al,2006, 14), resulting in irremediable subsequence in macro- management of the country which is not desirable regarding the macroorientation in the fourth and fifth Rule Program and the Twenty Year Perspective Document of Iran to economic and social mutation relying on knowledge oriented strategy. If the public organizations compared to the private sector, want to provide the citizen with good services in future, they should have an organizational knowledge strategy which the present article discusses it with posing the following important questions:

- What is the condition of the knowledge strategy in the Iranian governmental organizations (Electricity Industry) at present?

- How should be the condition of the Iranian governmental organizations in 2025 AD Perspective?

- What is the optimum combination of knowledge strategies for filling the gap of knowledge in the Iranian governmental organizations (Electricity Industry)?

- What is the appropriate pattern to achieve this end?

\section{Review of Literature:}

Nowadays, many of the managers accredit knowledge to be a strategic property of their organization and in the view of the majority of the successful organizations' managers in the world, knowledge is considered as the best property for the third millennium organization (Aggestam, 2006,26) . In this regard, Peter Dracker( 1992) believes that nowadays the economic resources of the organizations and productions tools are not the financial capital, natural resources and- or work force, but this resource is the knowledge. Based on a survey, conducted on 200 superior organizations and companies around the world in different fields, more than $88 \%$ of the managers have cited the knowledge management as the second work propriety. With this purpose, in the table of organizations' equivalency model of scores which has been revised in the National Quality Program of Baldridge in 2010, the knowledge management scores the most after the parameters related to the leadership and consequences (NIST 2010).

The process of knowledge management helps the organizations to perform their mission well and to reach their outlook and goals. To this end, the concept of strategy has emerged in the management literature in order to define what are the organizations' knowledge gaps of the as well as why they are strategic and required 
for the organizations. It is believed that before the disposition of the knowledge management systems, the knowledge strategies of the organization must be first planned on the bases of which the organization is to find what certain strategies perform the process of knowledge management (Choi et al, 2006). Hence, the knowledge strategies in a public organization define the fact that what knowledge, in what depth, from what source and in what way it must achieved and distributed. Studies show that about $40 \%$ of the successful organizations in the world possess knowledge strategies and about another $41 \%$ have been also performing programs with the same purpose (Fahey, 2006).

Bierly and Chakrabarti (1996) are considered as the pioneers of the experimental studies in the area of knowledge strategies. These writers define knowledge strategies as the collective reaction of the managers to the needs for strategic learning of the organizations. The managers are also in need of considering the learning prospective (external or internal), the nature of learning (basic or trivial/gradual), the learning speed (quick or slow), and the knowledge base (deep or shallow), make the strategic decisions. They have performed the studies from 1977 to 1991 on knowledge strategies on 21 pharmacy companies in the United States. The investigators in the field of knowledge strategy divide into four groups of innovative, exploiter, seeker, and reclusive based on the force and the speed of learning (quick/slow), depth of the required knowledge (vast/deep), the type of organizational learning (internal/external and basic/gradual).

Bierly and Daly (2002) define the knowledge strategy as: a collection of strategic selections of the organizations by taking into consideration the two aspects of knowledge: 1 . Generating and grasping new knowledge, 2. Applying and benefiting from the present knowledge to create new productions and organizational processes. Zack (1999) analyzing 25 organizations conclude that organizational knowledge can be classified into three groups: (the basic knowledge/advanced knowledge, and innovative knowledge). Comparing the base of an organization's knowledge with that of opponent organizations, Zack suggests a framework on basis of which organizations can be broken down into four categories as at risk, knocked out, remaining in the competitive manner, and innovative ones. In order to expand his theoretical framework, he then uses the definition of "knowledge gap" that is the distance between what an organization knows and what it must know and the (strategic gap): the difference between what an organization can done and what it must do the basic elements in one knowledge strategy. By taking this perspective into consideration, he defines the knowledge strategy as the ability to establish equilibrium between the source-based knowledge and the required abilities for present goods and services. In his view, disposition of the knowledge strategy in one organization can help bridge the knowledge gap. This definition is illustrated in the Figure 1 (Zack, 1999).
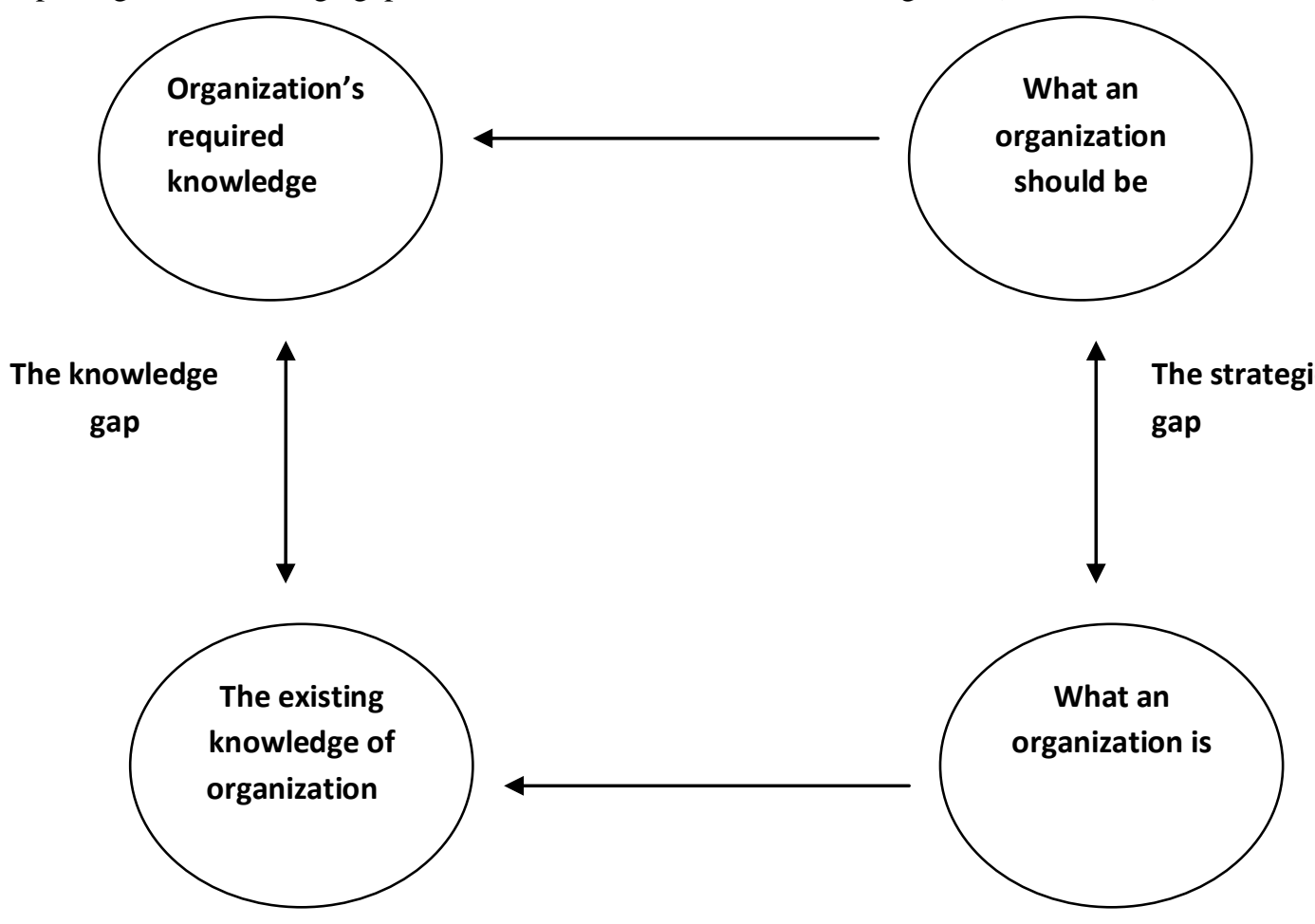

Figure 1: the definition of knowledge gap

Skyrme (2002) gives some suggestions about the knowledge strategy. He believes that the organizations can choose one of the following strategies: 1.Learning from what an organization knows - like getting aware of 
knowledge, sharing it and making use of the internal or the external knowledge. 2. Better innovations working faster- like a better changing of the ideas into goods and services.

Abou-Zeid (2002) investigated the knowledge strategy in its both internal and external factors. Being affected by Zack's view (1999), he introduces the knowledge strategy as the parameter which creates a balance between the opportunities and the threats in the external environment and points of weaknesses and strengths in the internal environment. From Abu-Zeid's point of view, the external environment's aspects of the knowledge strategy are knowledge territory (what the organization should know), systematic capabilities (the required knowledge features) and knowledge dominance (the way of gaining the required knowledge). He also believes the internal environment's aspects of the knowledge strategy to be the knowledge substructure (technical/ structural and cultural), processes (the activities done as the result of new knowledge), and skills (technical/ organizational and humane).

Choi and Lee (2003) performing some studies in the South Korean manufactory/financial, and service organizations investigated the objective and subjective dimensions of the knowledge strategy in the imagined organizations. Their study was based on the hypothesis that there is a direct relation between the level of the activities and the knowledge aspects. Thus, the investigators based on the findings of this study and in a $2 \times 2$ matrix considered four strategies of the knowledge management as: passive strategy ( less subjective/less objective), system-based strategy ( less subjective/ more objective), human-based strategy ( more subjective/less objective) and dynamic strategy( more subjective/less objective). Based on their studies, they claimed that the dynamic strategy is the most profitable one for organizations.

Gold et al (2001), in an experimental study relying on the organizational capabilities, suggested four knowledge strategies including codifying strategy (objective content and process capability), exploiting strategy (subjective content and process capability), integrity strategy (objective content and sub-structure capability) and growth strategy ( subjective content and sub-structure capability).

In a case study on manufactory/sanitary and consulting organizations, Hansen et al (2001), identified two knowledge management strategies as codifying and personalizing. The investigators warn that these strategies shall not be used in an organization in an equal manner. They recommend that they should be used in 20/80 percentages.

Based on a case study done one 31 different projects of the knowledge management in 23 countries, Davenport \& Prusak (2000) suggested a typology of knowledge management strategy consisting of four groups including the way of knowledge accumulation/access to knowledge/knowledge environment and knowledge properties. They identified the parameters like the knowledge-based culture/technical and organizational substructure/chief managers support/the relationship between the knowledge manager and gaining economic profits/positive view/honesty in speech/considerable motivational supporter/the level of knowledge structure, and different channels for the knowledge flow that would help the success of knowledge management strategies.

The main variables in the current study are as follows:

\section{The source of knowledge}

Barchan (1999) believes that when one leaves an organization conveys something more than his knowledge which is the capital applied to occupational maturity as well as his experience. It would take a long time for another one to reach the same level of knowledge and experience. Also, according to Brooking (1996), only $20 \%$ of people's knowledge will be used in the organization. This illustrates that for confronting with such issues, organizations should have processes to conquer the knowledge of individuals and also use their ideas and internal beliefs in order to create knowledge in their organizations. Knowledge creation can be done through different ways; one of them is investigation and development. Establishing investigation and development unit for exploiting from the existing knowledge in the organization and/or gaining knowledge through the organization's external sources is fruitful. Mc Adam and Reid (2000) suggested other suitable solutions such as force gaining or buying intellectual capital like Patent, investigatory documentations, consulting contracts, and also the possibility of internet search and sharing knowledge with other industries. Learning is also the other method of knowledge creation and the human sources play an important role in that way. In personal learning, each individual tends to exploit the others' experiences, but the organizational learning will be crystalized on all levels of the organization and thus it requires the culture of knowledge creation.

\section{Knowledge Accumulation}

The goal of organizing and accumulating knowledge is to make possible recycling and also access to it. It includes processes like documentation, formulation, externalization, translation, classification and updating of the knowledge. In the realm of the governmental organizations, the relations are mostly verbal and formal (Dally and Hamilton, 2000). Because of that the transferred knowledge is often recorded and documented. For storing and organizing the knowledge, the organizations require knowledge storage. The governmental organizations have appropriate capacity for keeping the knowledge storage. In case of having storage for 
keeping and storing knowledge, the risk of losing it by staff's leaving will be decreased considerably. For knowledge accumulation, two strategies of codifying and personalizing are used. In the personalizing strategy, the transferring of the experience is not possible through relations and/or informational processes and documentation, but all which is transferred is an explanation of what we have experienced as well as insights and visions we have gained. The excremental knowledge is just created through the experimental learning process and transformational processes cannot generate experimental knowledge. The aim of the codifying strategy is to document a part of experimental knowledge created explicitly. It is capable of being written and thus it can be taken from one staff and be accessible to others as a codified version.

\section{The Knowledge Flow}

The knowledge Flow is the process of the distribution of knowledge among the applicants. Since the governmental states have a vast environment, a vertical structure and high bureaucratic level the relation between the people is mostly unilateral, so the distribution of knowledge takes place in a slow manner. Overall, the governmental organizations' environment does not support distribution. The existing weak point in this field is the lack of intention of the individuals to transfer the knowledge that is considered as their power parameter. This issue is especially true about the experts (Sparrow, 2000). It also can be true about the managers, so they prefer to monitor their staff's learning in order to control the organization ( Matlay, 2000). One of the Knowledge Flow methods is to use electronic technology sub-structure is performed in the organization based on the technological applications. In this way, a channel will be established to achieve a vast amount of knowledge and the related transactions. The other knowledge flow method is to utilize cultural processes and enhancing human resources which is mostly reliant on human forces.

\section{Base of Knowledge}

Base of knowledge indicates the level of knowledge which is emphasized in the organization. Theorists define the levels of knowledge in organizations as: knowledge-based or original which is the base level of knowledge required by all members of a certain industry. This knowledge does not illustrate a competitive advantage, but it is the required knowledge to be utilized in a certain realm. Advanced knowledge provides the organization with a superior domain. This kind of knowledge differentiates between the imagined organization and others due to utilizing knowledge in different ways. Innovative knowledge enables the organizations to be the pioneer. This kind of knowledge allows the organizations to change the strategy of one part and this leads to its certain difference from the other organizations.

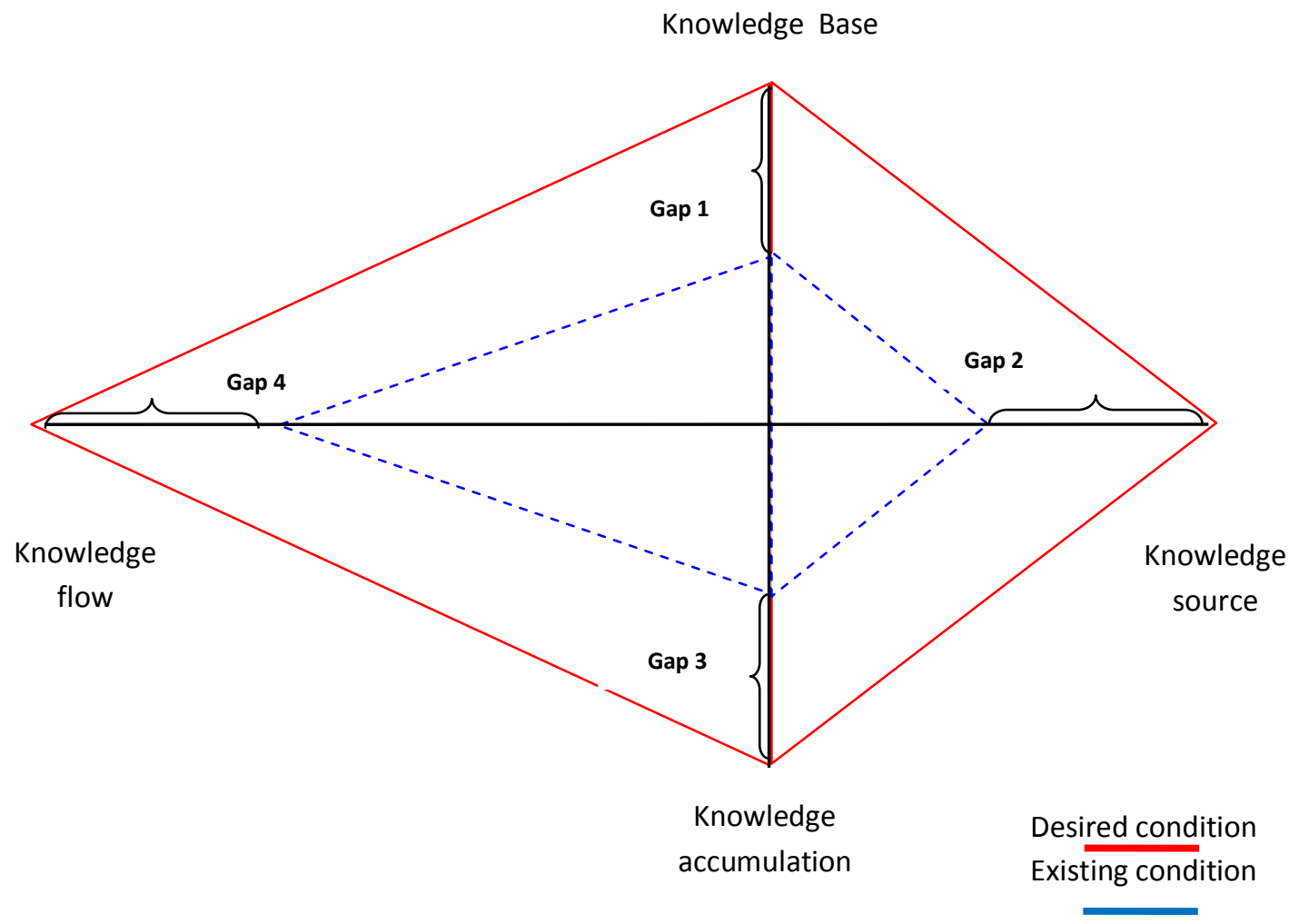

Figure 2: Conceptual pattern of study 


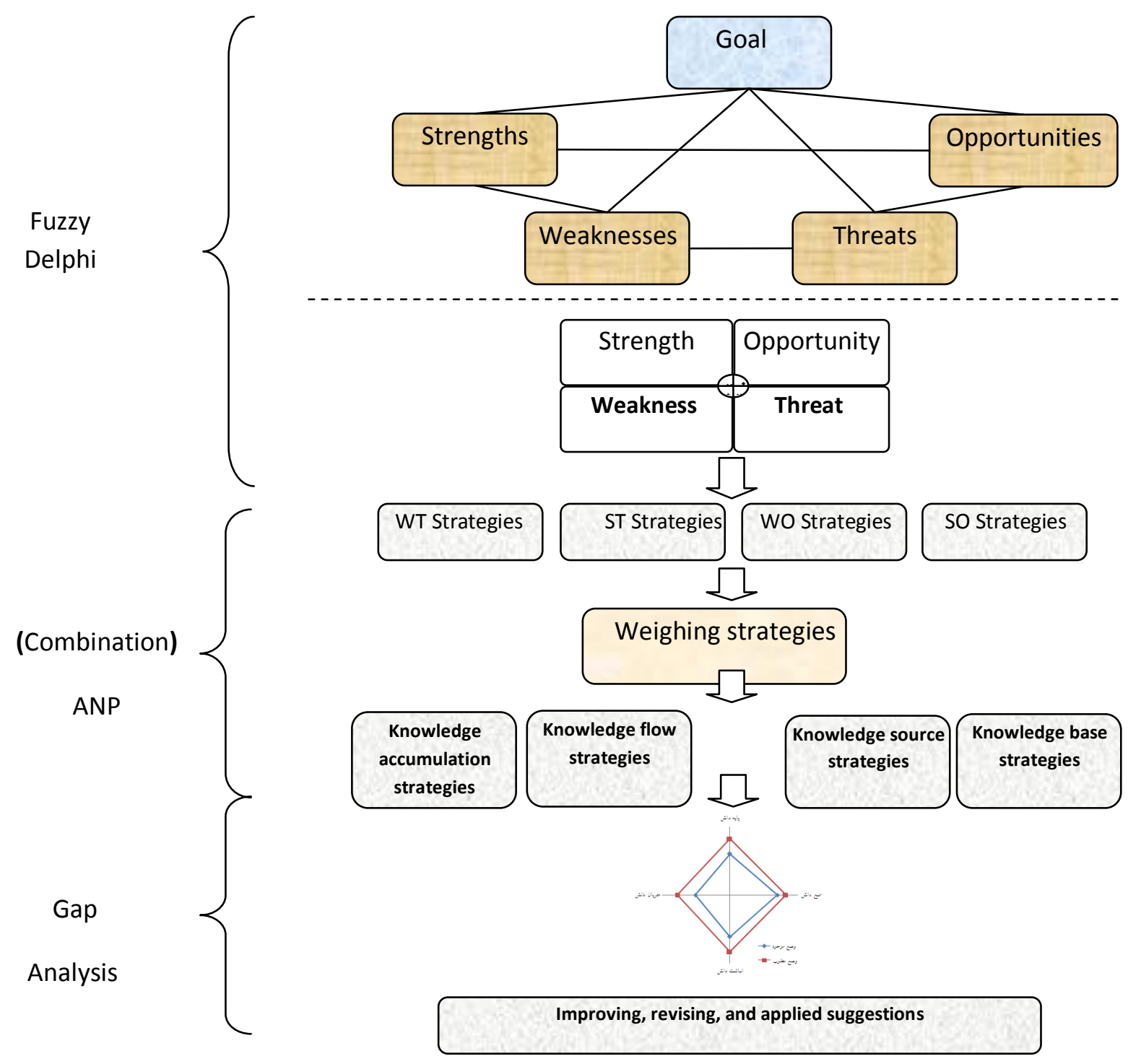

Figure 3: The stages of the study

\subsection{Method}

\section{Methodology}

Since the main issue in the research is to present knowledge strategy pattern that can lead into the enhancement of the level of the operation of the organization, the present study is to be more developing one making use of quantitative data to describe the facts. This study also is an applied one due to presenting some strategy to decreasing the knowledge gap.

\subsection{Instruments and data collection}

The required data was collected by library work, sending questionnaires to chief managers of companies linked to the Electricity Industry, experts, and the theorists in the realm of knowledge management and strategic planning and management. Also, in this study, discovering interviews were done.

\subsection{Participants}

The participants in this study are Tavanir Company, Iranian Electricity network management, Energy exploiting organization, Iranian new energies organization, and power development organization of Iran consisting of 1452 personnel together. Based on the sampling model, 137 ones were selected as the statistical sample. 


\subsection{Data analysis}

In the process of the study, first, the manner of identifying the main hypothesis of the knowledge strategy in governmental organizations (Electricity Industry) was taken into consideration. The main hypotheses include the external environmental parameters (opportunities and threats) and the internal environmental parameters (strengths and weaknesses). These hypotheses, on the one hand, root in the research theoretical bases and on the other hand have been taken from the expert group's views which were refined relying on the Fuzzy Delphi method. Then, applying the Network Analysis Process method, the weight ratio of the conceptual framework's variables and their relation was extracted and finally using the Gap Analysis the distance between the current condition and the desired knowledge strategy was analyzed. To extract the main hypotheses of knowledge strategies, variables based on the theoretical bases of the study were given to 30 qualified experts in industry which was refined relying on Fuzzy Delphi method as shown in Figure 3.

In this study, questionnaires were planned with the aim of consulting with the experts on their agreement level with the pattern variables and standards. Hence, the experts could express the level of agreement using lingual variables like fully disagree, disagree, neutral, agree, and fully agree. Since the different characteristics of people affect their mental interpretations about the qualitative variables, defining the domain of the qualitative variables, experts have answered the questions with the same mentality.

In the first survey, the environmental hypotheses of knowledge strategy are introduced in four categories (opportunities, threats, strengths, and weaknesses) and a brief description on each one has been given to the members of the experts group. Then, their agreement level to each variable and their corrective suggestions for were collected.

Table 1: A Sample of counting the results from the responses in the first stage of the survey

\begin{tabular}{l} 
Variables \\
\hline The frequency of educated and experts in the country
\end{tabular}

Regarding the offered alternatives and the defined lingual variables $A_{i}=\left(a_{1}^{(i)}, a_{2}^{(i)}, a_{3}^{(i)}\right), i=1,2,3, \ldots, n$ the questionnaire, the results from the given responses has been presented in the figure 2. According to the results in this figure, the Fuzzy mean in each variable has been calculated as follow:

Formula 1: $\quad A_{i}=\left(a_{1}^{(i)}, a_{2}^{(i)}, a_{3}^{(i)}\right), i=1,2,3, \ldots, n$

Formula 2:

$$
A_{\text {ave }}=\left(m_{1}, m_{2}, m_{3}\right)=\left(\frac{1}{n} \sum_{i=1}^{n} a_{1}^{(i)}, \frac{1}{n} \sum_{i=1}^{n} a_{2}^{(i)}, \frac{1}{n} \sum_{i=1}^{n} a_{3}^{(i)}\right)
$$

In this relation $A_{i}$ represents the view of the expert number I and $A_{\text {ave }}$ the mean of the viewpoint of them. This means that frequency for the survey items ( for example "fully agree" has been multiplied by triangular numbers and is then divided to 30 which represent the number of the responses. In this way we can calculate the triangular fuzzy mean for each environmental hypothesis. A summary of the results is illustrated in the table 2 .

Table 2: A Sample of the mean of the viewpoint of the expert in the first stage of the survey 


\begin{tabular}{|c|c|c|}
\hline Variables & $\begin{array}{c}\text { Mean of the } \\
\text { triangular Fazy } \\
(m, \alpha, \beta)\end{array}$ & $\begin{array}{c}\text { The de-fuzzed } \\
\text { mean }\end{array}$ \\
\hline The frequency of educated and experts in the country & $(0 / 73,0 / 19,0 / 12)$ & 0,71 \\
\hline $\begin{array}{l}\text { The willingness of the experts and intellectuals to } \\
\text { collaborate with the power and energy industry }\end{array}$ & $(0 / 68,0 / 18,0 / 15)$ & 0,37 \\
\hline ............. & & $\ldots$. \\
\hline The culture of learning inside the organization & $(0 / 75,0 / 20,0 / 09)$ & 0,72 \\
\hline $\begin{array}{l}\text { The amount of collaboration with the scientific and research } \\
\text { centers inside and outside the country }\end{array}$ & $(0 / 82,0 / 22,0 / 09)$ & 0,29 \\
\hline
\end{tabular}

The confirmed achieved mean illustrates the intensity of experts' agreement with each main hypothesis of the knowledge strategy. As the tables 2 and 3 show, the most amount of experts' agreement with each main hypothesis of the knowledge strategy include: the ability to have access to the modern technology as well as transferring it. Scientific and specialized capability of the active counselors and contractors in the fields of power and energy ( in opportunities), the amount of collaboration between the universities and the research centers and power and energy industry, the condition of the existing technologies in the country( in threats), the reduction of the financial sources for research, the quantity and quality of the expert work forces, the ability of using internal consolers' services(in strengths), the ability to have access to the modern technology as well as transferring it and the ability to employ and keeping academic work forces(in weaknesses). This survey was done for three times. The parameters selected as the environmental hypotheses were revised by consulting with one the experts and the results are summarized in table 4.

Table 3: Environmental hypotheses of knowledge strategies (opportunities, threats, strengths, weaknesses)

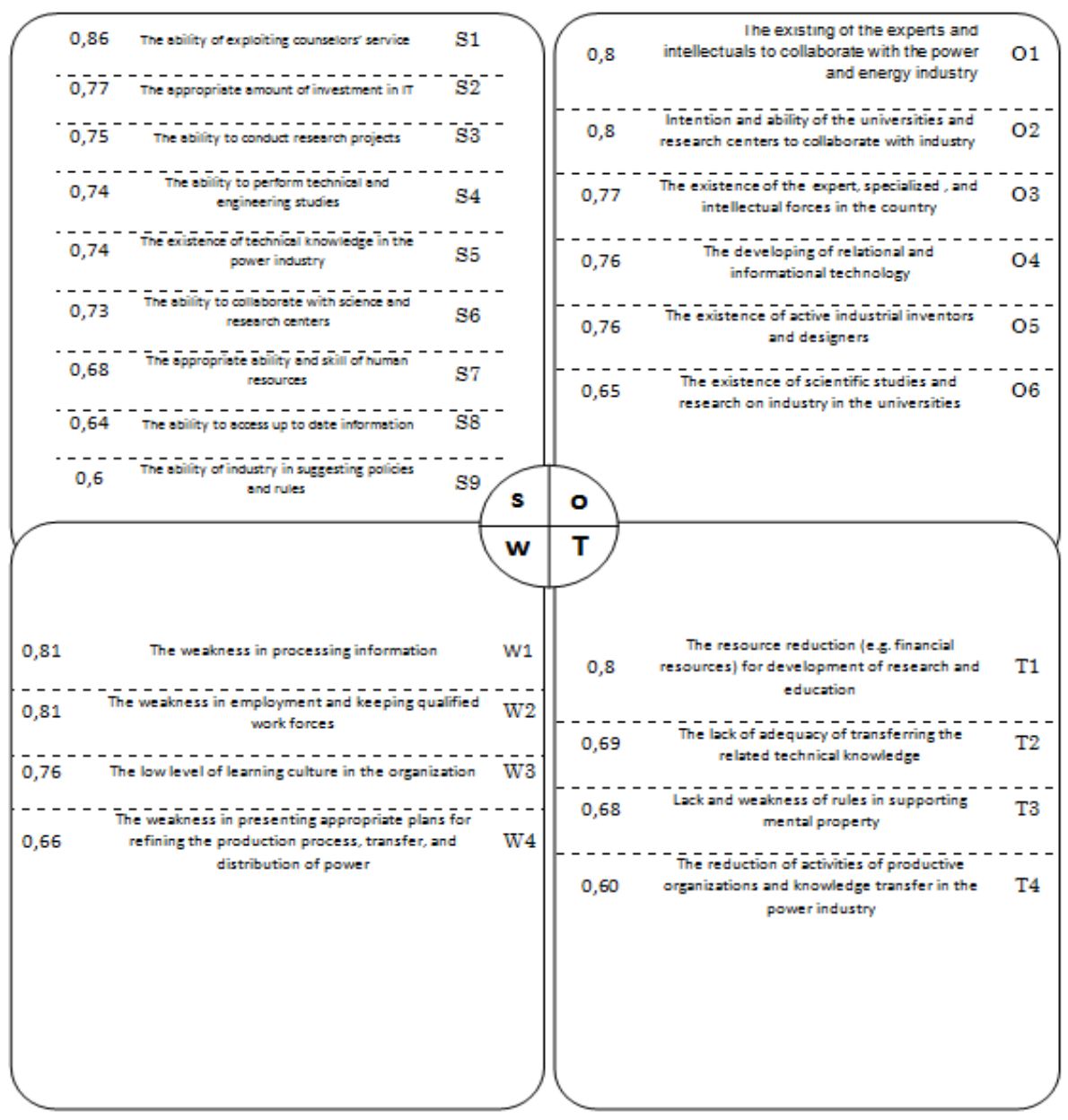




\subsection{Determining and prioritizing the knowledge strategies}

After identifying and determining the amount of knowledge strategy's environmental hypotheses' priority in the industry, firstly, using the SWOT matrix logic and benefiting from the experts' views knowledge strategies were extracted. These strategies were revised in a canonical session with experts. Regarding the SWOT matrix logic as the source for planning knowledge strategies, a collection of strategies were suggested and then revised by the experts at first a primitive list of the knowledge strategy was provided which was given to the experts in the canonical session. Overall, 27 strategies were suggested to the experts: these strategies were presented regarding strategies of the Electricity Industry as well as strategies related to those of knowledge. At first, the experts were asked to revise these strategies as well as to determine the related hypotheses and classify then to four categories of knowledge source, knowledge base, knowledge flow and knowledge accumulation. The results are summarized in the following table:

Table 4: A sample of knowledge strategies

\begin{tabular}{|c|c|c|c|}
\hline $\begin{array}{l}\text { Studying the application of innovative methods of transferring and } \\
\text { storing power: superconductor, (EHV), (HVDC),( FACTS), } \\
\text { batteries, compressed air, hydrogen, }\end{array}$ & $\mathrm{S}_{4} \mathrm{O}_{3}$ & SO1 & \multirow{4}{*}{$\begin{array}{l}\text { Knowledge } \\
\text { Base }\end{array}$} \\
\hline $\begin{array}{l}\text { Disposition and establishment of professional license system in } \\
\text { the power industry }\end{array}$ & $\mathrm{W}_{2} \mathrm{O}_{3}$ & WO1 & \\
\hline Supporting moral ownership and technical knowledge producer & $\mathrm{S}_{9} \mathrm{~T}_{3}$ & ST1 & \\
\hline $\begin{array}{l}\text { Supporting, writing and publishing books, scientific articles and } \\
\text { theses related to the power industry }\end{array}$ & $\mathrm{W}_{4} \mathrm{~T}_{2}$ & WT1 & \\
\hline $\begin{array}{l}\text { Bilateral collaboration and sharing in projects with scientific and } \\
\text { research centers }\end{array}$ & $\mathrm{S}_{1,4,6} \mathrm{O}_{1,2,6}$ & $\mathrm{SO} 2$ & \multirow{4}{*}{$\begin{array}{l}\text { Knowledge } \\
\text { Source }\end{array}$} \\
\hline Providing instructors with study opportunities in power industry & $\mathrm{W}_{2,3} \mathrm{O}_{1,3}$ & WO2 & \\
\hline $\begin{array}{l}\text { Internal development, identifying and domesticizing the } \\
\text { technologies }\end{array}$ & $\mathrm{S}_{6} \mathrm{~T}_{2}$ & ST2 & \\
\hline $\begin{array}{l}\text { Establishing the refine system of scientific and technical changes } \\
\text { in world's power industry }\end{array}$ & $\mathrm{W}_{1} \mathrm{~T}_{4}$ & WT2 & \\
\hline $\begin{array}{l}\text { Expanding the culture of collaboration as well as keeping } \\
\text { knowledge through making a creative and knowledge based } \\
\text { environment }\end{array}$ & $\mathrm{S}_{8} \mathrm{O}_{6}$ & $\mathrm{SO} 3$ & \multirow{4}{*}{$\begin{array}{l}\text { Knowledge } \\
\text { Accumulation }\end{array}$} \\
\hline $\begin{array}{l}\text { Documenting the knowledge and experience of the power industry } \\
\text { as well as disposing the system of knowledge keeping }\end{array}$ & $\mathrm{W}_{1} \mathrm{O}_{4}$ & WO3 & \\
\hline $\begin{array}{l}\text { Updating the system of organizational knowledge registration in } \\
\text { the power industry }\end{array}$ & $\mathrm{S}_{6} \mathrm{~T}_{4}$ & ST3 & \\
\hline $\begin{array}{l}\text { Evaluating and rating the registered knowledge in the power } \\
\text { industry }\end{array}$ & $\mathrm{W}_{1} \mathrm{~T}_{1}$ & WT3 & \\
\hline $\begin{array}{l}\text { Developing the commercializing the conducted researches in the } \\
\text { field of power industry through required supports }\end{array}$ & $\mathrm{S}_{5} \mathrm{O}_{6}$ & $\mathrm{SO} 4$ & \multirow{4}{*}{$\begin{array}{l}\text { Knowledge } \\
\text { Flow }\end{array}$} \\
\hline $\begin{array}{l}\text { Developing and improving the capacities relying on establishing } \\
\text { management clinics as well as skill training }\end{array}$ & $\mathrm{W}_{4} \mathrm{O}_{2}$ & WO4 & \\
\hline $\begin{array}{l}\text { Revising and updating the trainings as well as transferring the } \\
\text { concepts related to the power industry technologies }\end{array}$ & $\mathrm{S}_{6} \mathrm{~T}_{2}$ & ST4 & \\
\hline $\begin{array}{l}\text { Establishing and expanding the network of industry knowledge for } \\
\text { the activities done by experts and specialists }\end{array}$ & $\mathrm{W}_{2} \mathrm{~T}_{3}$ & WT4 & \\
\hline
\end{tabular}

Since one of the requirements of operative application of these strategies is to find relationships between the strategies as well as to determine their weight ration. Thus, in the present study, the network model of processes analysis is used, due to the high accuracy of this model in analyzing the relations between variables as well as extracting the weight ration regarding the effects of strategies on each other.

\section{3- Determining the branches and relations between the parameters}

Regarding the identified strategies, four types of strategies are used to branch the parameters and each strategy is selected as an element of each branch. 


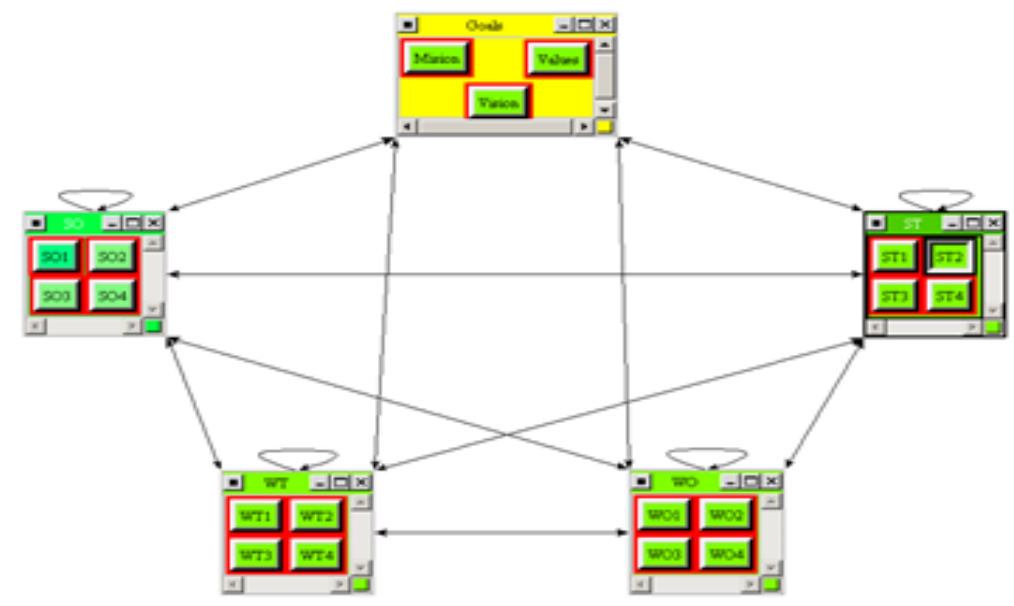

Figure 4: A general Scheme from the the model of the process of the Analatic Network Process

As the above figure shows, not only there is a mutual relation between the goal (perspective, mission and values), branches (the developmental strategies, solving the internal challenges and defensive) and elements (different types of strategies), the elements and branches also affect themselves. This has been presented by the big arrow in the above figure. Also, each element in each branch affects the other ones in the same branch as well as the other elements in the other branches while itself being affected. The direction of the arrows in the figure shows the way the act of affecting occurs between the branches and elements. In other words, the direction is depicted from the independent element to the dependent element.

\section{Performing pair comparisons:}

According to the solidarity and attachment between the branches and the elements, the pair comparison process has been used here. In this process three forms of comparison have been done: the pair comparison of the branches, the pair comparison of the elements inside each branch and a pair comparison based on the affecting levels that exists between them. These comparisons have been done by using the software Super Decisions and by making use of the geometrical mean of the view of the experts.

The pair comparison of the branches: Each branch has been put into comparison by taking into consideration the goal in this way:

\begin{tabular}{c|cccc}
\hline \multicolumn{5}{c}{ Table 5: The Pair Comparison of the branches } \\
\hline & developmental & conservative & competetive & defensive \\
\hline developmental & 1 & $1 / 38$ & $1 / 09$ & $1 / 01$ \\
conservative & $0 / 72$ & 1 & $0 / 71$ & $2 / 98$ \\
competetive & $0 / 92$ & $1 / 41$ & 1 & $1 / 08$ \\
defensive & $0 / 99$ & $0 / 36$ & $0 / 93$ & 1
\end{tabular}

The feature of the pair comparison of the branches

\begin{tabular}{|l|l|l|}
\hline \multicolumn{3}{|c|}{ Inconsistency: 0.09360} \\
\hline SO & & 0.26742 \\
\hline ST & & 0.26076 \\
\hline WO & & 0.28648 \\
\hline WT & & 0.18534 \\
\hline
\end{tabular}

As it can be seen the branches of conservative strategies is the most important one, and the branch of the defensive strategies is the least important one. As the level of incompatibility is 0.0936 and it is lower than 0,1 , it can be said that the result from the especial vector is reliable.

The Pair Comparison of the elements inside each branch: Each element inside the branch has been compared in pair with another pair. As an example the pair comparison of the elements inside the branch of the developmental strategies has been discussed. 


\section{Table 6: The Pair Comparison of the elements inside the branch of the} developmental strategies

\begin{tabular}{c|cccc}
\hline & SO1 & SO2 & SO3 & SO4 \\
\hline SO1 & 1 & $0 / 9$ & $0 / 72$ & 1 \\
SO2 & $1 / 1$ & 1 & $0 / 68$ & $1 / 22$ \\
SO3 & $1 / 37$ & $1 / 46$ & 1 & $1 / 3$ \\
SO4 & 1 & $0 / 81$ & $0 / 76$ & 1
\end{tabular}

The special vector of the pair comparison of the elements in developmental strategies

\begin{tabular}{||l|l|l|}
\hline \multicolumn{3}{|c|}{ Inconsistency: 0.00336} \\
\hline $\mathrm{SO} 1$ & & 0.22133 \\
\hline $\mathrm{SO} 2$ & & 0.24245 \\
\hline $\mathrm{SO} 3$ & & 0.31586 \\
\hline $\mathrm{SO} 4$ & & 0.22035 \\
\hline
\end{tabular}

In order to calculate the weight ratio of the strategies from the limited matrix, the fix numbers in the rows related to the strategies, resulted from the limited matrix on a scale of number one; then by taking into consideration of the weight ration of each strategy in comparison to its mission, the perspective and values are calculated. The results are illustrated in table 7.

Table 7: Special vector of the developmental strategies

\begin{tabular}{|c|c|c|c|c|}
\hline \multicolumn{3}{|c|}{ Elements (Knowledge strategies) } & \multicolumn{2}{|c|}{ Branches } \\
\hline Wight in total & $\begin{array}{c}\text { Wight inside } \\
\text { branch }\end{array}$ & Strategy code & Branch weight & Strategy kind \\
\hline 0,0592 & 0,2213 & SO1 & \multirow{4}{*}{0,2674} & \multirow{4}{*}{$\mathrm{SO}$} \\
\hline 0,0648 & 0,2425 & $\mathrm{SO} 2$ & & \\
\hline 0,0845 & 0,3159 & $\mathrm{SO} 3$ & & \\
\hline 0,0589 & 0,2224 & $\mathrm{SO} 4$ & & \\
\hline 0,0762 & 0,2661 & WO1 & \multirow{4}{*}{0,2865} & \multirow{4}{*}{ WO } \\
\hline 0,0739 & 0,2579 & WO2 & & \\
\hline 0,0709 & 0,2476 & WO3 & & \\
\hline 0,0654 & 0,2283 & WO4 & & \\
\hline 0,0653 & 0,2504 & ST1 & \multirow{4}{*}{0,2608} & \multirow{4}{*}{ ST } \\
\hline 0,0696 & 0,2668 & ST2 & & \\
\hline 0,0693 & 0,2657 & ST3 & & \\
\hline 0,0566 & 0,2171 & ST4 & & \\
\hline 0,0530 & 0,2859 & WT1 & \multirow{4}{*}{0,1853} & \multirow{4}{*}{ WT } \\
\hline 0,0408 & 0,2200 & WT2 & & \\
\hline 0,0547 & 0,2952 & WT3 & & \\
\hline 0,0368 & 0,1989 & WT4 & & \\
\hline 1,0000 & 4,0000 & - & 1,0000 & total \\
\hline
\end{tabular}

As it can be seen, the third developmental strategy possesses the highest importance ratio and the fourth defensive strategy the lowest. By taking into consideration the gained weight for each strategy, the final list of the knowledge strategies will be so according to their priority: 
Table 8: The priority of knowledge strategies

\begin{tabular}{|c|c|c|c|}
\hline row & Strategy & $\begin{array}{c}\text { Strateg } \\
\text { y } \\
\text { code }\end{array}$ & weight \\
\hline 1 & Supporting the moral ownership of the producers of technical knowledge & $\mathrm{SO} 3$ & 0,0845 \\
\hline 2 & $\begin{array}{l}\text { Doing mutual collaboration and projects in collaboration with science and } \\
\text { research centers }\end{array}$ & WO1 & 0,0762 \\
\hline 3 & $\begin{array}{l}\text { Study opportunities for the universities' scientific boards in the case of } \\
\text { power industry }\end{array}$ & WO2 & 0,0739 \\
\hline 4 & Internal development, identifying and domesticizing the technologies & WO3 & 0,0709 \\
\hline 5 & $\begin{array}{l}\text { Documenting the knowledge and experience of the power industry as well } \\
\text { as disposing the system of knowledge keeping }\end{array}$ & ST2 & 0,0696 \\
\hline 6 & $\begin{array}{l}\text { Updating the system of organizational knowledge registration in the power } \\
\text { industry }\end{array}$ & ST3 & 0,0693 \\
\hline 7 & $\begin{array}{l}\text { Establishing the refine system of scientific and technical changes in } \\
\text { world's power industry }\end{array}$ & WO4 & 0,0654 \\
\hline 8 & $\begin{array}{l}\text { Expanding the culture of collaboration as well as keeping knowledge } \\
\text { through making a creative and knowledge based environment }\end{array}$ & ST1 & 0,0653 \\
\hline 9 & $\begin{array}{l}\text { Disposition and establishment of professional license system in the power } \\
\text { industry }\end{array}$ & $\mathrm{SO} 2$ & 0,0648 \\
\hline 10 & $\begin{array}{l}\text { Studying the application of innovative methods of transferring and storing } \\
\text { power: superconductor, (EHV), (HVDC), ( FACTS), batteries, compressed } \\
\text { air, hydrogen... }\end{array}$ & SO1 & 0,0592 \\
\hline 11 & $\begin{array}{l}\text { Supporting, writing and publishing books, scientific articles and theses } \\
\text { related to the power industry }\end{array}$ & $\mathrm{SO} 4$ & 0,0589 \\
\hline 12 & Evaluating and rating the registered knowledge in the power industry & ST4 & 0,0566 \\
\hline 13 & $\begin{array}{l}\text { Revising and updating the trainings as well as transferring the concepts } \\
\text { related to the power industry technologies }\end{array}$ & WT3 & 0,0547 \\
\hline 14 & $\begin{array}{l}\text { Developing the commercializing the conducted researches in the field of } \\
\text { power industry through required supports }\end{array}$ & WT1 & 0,053 \\
\hline 15 & $\begin{array}{l}\text { Developing and improving the capacities relying on establishing } \\
\text { management clinics as well as skill training }\end{array}$ & WT2 & 0,0408 \\
\hline 16 & $\begin{array}{l}\text { Establishing and expanding the network of industry knowledge for the } \\
\text { activities done by experts and specialists }\end{array}$ & WT4 & 0,0368 \\
\hline
\end{tabular}

Gap Analysis:

One of the main issues regarded by the present study is the analysis of the existing distance of the knowledge strategy in the power industry from knowledge strategy. In other words, if the knowledge management is planned and performed in the companies of the power industry, to what extent it has been based on the strategy? Does it support the prior strategies? These are the questions being taken into consideration in this part of the study. To put this issue into analysis in the third part of the study, relying on the questionnaire the gap analysis was done with the help of the governmental organizations of the Electricity Industry staff.

Table 9: Multiplying each strategy by its gap, indicator of the main priorities of improvement and change of strategies to have knowledge -based organization

\begin{tabular}{|c|c|c|c|c|c|c|c|}
\hline \multirow{2}{*}{$\begin{array}{l}\text { Priority of } \\
\text { improvement }\end{array}$} & \multirow{2}{*}{ distance } & \multicolumn{2}{|c|}{ condition } & \multirow{2}{*}{ weight } & \multirow{2}{*}{ Strategy } & \multirow{2}{*}{ code } & \multirow{2}{*}{ vector } \\
\hline & & appropriate & existing & & & & \\
\hline 0.0017 & 0.03 & 4.13 & 4.10 & 0.06 & $\begin{array}{l}\text { Studying the } \\
\text { application of } \\
\text { innovative methods of } \\
\text { transferring and storing } \\
\text { power: superconductor, } \\
\text { (EHV), (HVDC),( } \\
\text { FACTS), batteries, } \\
\text { compressed air, } \\
\text { hydrogen... }\end{array}$ & SO1 & $\begin{array}{l}\text { Knowledge } \\
\text { base }\end{array}$ \\
\hline
\end{tabular}




\begin{tabular}{|c|c|c|c|c|c|c|c|}
\hline 0.0641 & 0.83 & 3.43 & 2.60 & 0.08 & $\begin{array}{l}\text { Disposition and } \\
\text { establishment of } \\
\text { professional license } \\
\text { system in the power } \\
\text { industry }\end{array}$ & WO1 & \\
\hline 0.2175 & 3.33 & 4.57 & 1.23 & 0.07 & $\begin{array}{l}\text { Supporting the moral } \\
\text { ownership of the } \\
\text { producers of technical } \\
\text { knowledge }\end{array}$ & ST1 & \\
\hline 0.0164 & 0.31 & 4.50 & 4.19 & 0.05 & $\begin{array}{l}\text { Supporting, writing and } \\
\text { publishing books, } \\
\text { scientific articles and } \\
\text { theses related to the } \\
\text { power industry }\end{array}$ & WT1 & \\
\hline 0.0430 & 0.66 & 4.10 & 3.43 & 0.06 & $\begin{array}{l}\text { Doing mutual } \\
\text { collaboration and } \\
\text { projects in } \\
\text { collaboration with } \\
\text { science and research } \\
\text { centers }\end{array}$ & SO2 & \multirow{4}{*}{$\begin{array}{l}\text { Knowledge } \\
\text { source }\end{array}$} \\
\hline 0.1082 & 1.46 & 3.79 & 2.32 & 0.07 & $\begin{array}{l}\text { Study opportunities for } \\
\text { the universities' } \\
\text { scientific boards in the } \\
\text { case of power industry }\end{array}$ & wO2 & \\
\hline 0.0046 & 0.07 & 4.11 & 4.04 & 0.07 & $\begin{array}{l}\text { Internal development, } \\
\text { identifying and } \\
\text { domesticizing the } \\
\text { technologies }\end{array}$ & ST2 & \\
\hline 0.0126 & 0.31 & 4.54 & 4.23 & 0.04 & $\begin{array}{l}\text { Establishing the refine } \\
\text { system of scientific } \\
\text { and technical changes } \\
\text { in world's power } \\
\text { industry }\end{array}$ & WT2 & \\
\hline 0.1127 & 1.33 & 4.77 & 3.43 & 0.08 & $\begin{array}{l}\text { Expanding the culture } \\
\text { of collaboration as well } \\
\text { as keeping knowledge } \\
\text { through making a } \\
\text { creative and knowledge } \\
\text { based environment }\end{array}$ & $\mathrm{SO} 3$ & \multirow{4}{*}{$\begin{array}{l}\text { Knowledge } \\
\text { accumulation }\end{array}$} \\
\hline 0.0704 & 0.99 & 4.65 & 3.66 & 0.07 & $\begin{array}{l}\text { Documenting the } \\
\text { knowledge and } \\
\text { experience of the } \\
\text { power industry as well } \\
\text { as disposing the system } \\
\text { of knowledge keeping }\end{array}$ & WO3 & \\
\hline 0.0691 & 1.00 & 3.76 & 2.76 & 0.07 & $\begin{array}{l}\text { Updating the system of } \\
\text { organizational } \\
\text { knowledge registration } \\
\text { in the power industry }\end{array}$ & ST3 & \\
\hline 0.0613 & 1.12 & 3.49 & 2.37 & 0.05 & $\begin{array}{l}\text { Evaluating and rating } \\
\text { the registered } \\
\text { knowledge in the } \\
\text { power industry }\end{array}$ & WT3 & \\
\hline 0.0772 & 1.31 & 4.54 & 3.23 & 0.06 & $\begin{array}{l}\text { Developing the } \\
\text { commercializing the } \\
\text { conducted researches } \\
\text { in the field of power } \\
\text { industry through } \\
\text { required supports }\end{array}$ & SO4 & \multirow{4}{*}{$\begin{array}{l}\text { Knowledge } \\
\text { Flow }\end{array}$} \\
\hline 0.1439 & 2.20 & 3.43 & 1.23 & 0.07 & $\begin{array}{l}\text { Developing and } \\
\text { improving the } \\
\text { capacities relying on } \\
\text { establishing } \\
\text { management clinics as } \\
\text { well as skill training }\end{array}$ & WO4 & \\
\hline 0.0064 & 0.11 & 3.46 & 3.34 & 0.06 & $\begin{array}{l}\text { Revising and updating } \\
\text { the trainings as well as } \\
\text { transferring the } \\
\text { concepts related to the } \\
\text { power industry } \\
\text { technologies }\end{array}$ & ST4 & \\
\hline 0.0654 & 1.78 & 4.10 & 2.32 & 0.04 & $\begin{array}{l}\text { Establishing and } \\
\text { expanding the network }\end{array}$ & WT4 & \\
\hline
\end{tabular}




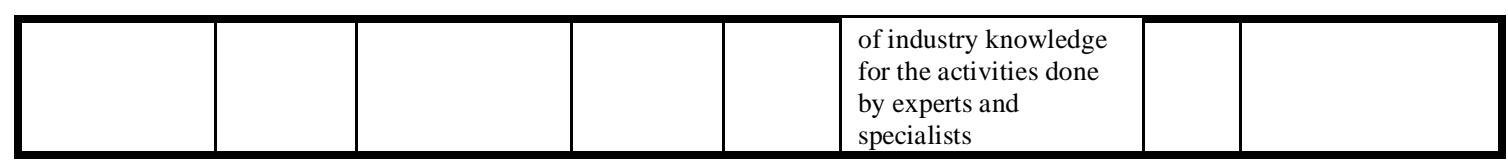

As it is shown in the table 9, the current state of knowledge management is different from the knowledge strategy of the organization in most cases. This reflects not much distance from the appropriate condition in case of some of the strategies ( for example Studying the application of innovative methods of transferring and storing power, Internal development, identifying and domesticizing the technologies, Revising and updating the trainings as well as transferring the concepts related to the Electricity Industry technologies). But in case of some other strategies (like supporting the moral ownership of the producers of technical knowledge, Expanding the culture of collaboration as well as keeping knowledge through making a creative and knowledge based environment, Developing and improving the capacities relying on establishing management clinics as well as skill training) there exists difference, much distance and they have much weight, so they must be taken as of the first priority for revision and refinement activities.

Table 10: Analyzing the distance and the refinement priority of the knowledge strategies

\begin{tabular}{|c|c|c|c|c|}
\hline priority & Distance & weight & Strategy & $e^{\operatorname{cod}}$ \\
\hline 0.2175 & 3.33 & 0.07 & $\begin{array}{l}\text { supporting the moral ownership of the producers of technical } \\
\text { knowledge }\end{array}$ & ST1 \\
\hline 0.1439 & 2.20 & 0.07 & $\begin{array}{l}\text { Developing and improving the capacities relying on establishing } \\
\text { management clinics as well as skill training }\end{array}$ & $4^{\text {WO }}$ \\
\hline 0.1127 & 1.33 & 0.08 & $\begin{array}{l}\text { Expanding the culture of collaboration as well as keeping } \\
\text { knowledge through making a creative and knowledge based } \\
\text { environment }\end{array}$ & $\mathrm{SO} 3$ \\
\hline 0.1082 & 1.46 & 0.07 & $\begin{array}{l}\text { Study opportunities for the universities' scientific boards in the } \\
\text { case of power industry }\end{array}$ & $2^{\text {WO }}$ \\
\hline 0.0772 & 1.31 & 0.06 & $\begin{array}{l}\text { Developing the commercializing the conducted researches in the } \\
\text { field of power industry through required supports }\end{array}$ & $\mathrm{SO} 4$ \\
\hline 0.0704 & 0.99 & 0.07 & $\begin{array}{l}\text { Documenting the knowledge and experience of the power industry } \\
\text { as well as disposing the system of knowledge keeping }\end{array}$ & 3 WO \\
\hline 0.0691 & 1.00 & 0.07 & $\begin{array}{l}\text { Updating the system of organizational knowledge registration in } \\
\text { the power industry }\end{array}$ & ST3 \\
\hline 0.0654 & 1.78 & 0.04 & $\begin{array}{l}\text { Establishing and expanding the network of industry knowledge } \\
\text { for the activities done by experts and specialists }\end{array}$ & $4^{\text {WT }}$ \\
\hline 0.0631 & 0.83 & 0.08 & $\begin{array}{l}\text { Disposition and establishment of professional license system in } \\
\text { the power industry }\end{array}$ & $1 \mathrm{WO}$ \\
\hline 0.0613 & 1.12 & 0.05 & $\begin{array}{l}\text { Evaluating and rating the registered knowledge in the power } \\
\text { industry }\end{array}$ & $3^{\text {WT }}$ \\
\hline 0.0430 & 0.66 & 0.06 & $\begin{array}{l}\text { Doing mutual collaboration and projects in collaboration with } \\
\text { science and research centers }\end{array}$ & $\mathrm{SO} 2$ \\
\hline 0.0164 & 0.31 & 0.05 & $\begin{array}{l}\text { Supporting, writing and publishing books, scientific articles and } \\
\text { theses related to the power industry }\end{array}$ & 1 WT \\
\hline 0.0126 & 0.31 & 0.04 & $\begin{array}{l}\text { Establishing the refine system of scientific and technical changes } \\
\text { in world's power industry }\end{array}$ & 2 WT \\
\hline 0.0064 & 0.11 & 0.06 & $\begin{array}{l}\text { Revising and updating the trainings as well as transferring the } \\
\text { concepts related to the power industry technologies }\end{array}$ & ST4 \\
\hline 0.0046 & 0.07 & 0.07 & $\begin{array}{l}\text { Internal development, identifying and domesticizing the } \\
\text { technologies }\end{array}$ & ST2 \\
\hline 0.0017 & 0.03 & 0.06 & $\begin{array}{l}\text { Studying the application of innovative methods of transferring and } \\
\text { storing power: superconductor, (EHV), (HVDC), ( FACTS), } \\
\text { batteries, compressed air, hydrogen... }\end{array}$ & SO1 \\
\hline
\end{tabular}

What went on illustrates the strategies which should be considered as the base in the organizational knowledge as well as change of system of knowledge management. The kind of changes will be presented in the suggestion part.

\section{Discussion and Conclusion}

The present paper, by posing some questions, was aimed to identify the knowledge strategies in the Iranian governmental organizations Electricity Industry, as well as making strategy changes in the imagined 
organizations' current knowledge to fill the gap between the considered condition in the horizons of the perspective and the current condition of the knowledge management in favor of dominant situation on the Iranian governmental organizations. To determine the knowledge strategies in governmental organizations, the main hypotheses of planning knowledge strategies in the internal and external realms were considered and using Fuzzy Delphi method the knowledge's opportunities, threats, strengths, and weaknesses were prioritized. Then relying on the questionnaire, the gap between the current condition and the desired condition was identified.

The findings of the gap analysis in case of Electricity Industry in the main realms of knowledge strategy (i.e. Knowledge base, knowledge source, knowledge flow, and knowledge accumulation) show that there is a meaningful gap between the current condition and the desired condition. Thus, the dimensions of the knowledge strategy in some fields requires qualitative improvements (ST2, ST4 and SO1), and in some cases revision and change in the knowledge management is required (ST1, SO3, WO4).

There is a meaningful gap in all four main realms of knowledge strategy in the current situation and the desired situation. Most notably, this matter is seen in case of knowledge base and knowledge flow. Thus, it is suggested to take some measures in the way of improvement of the current situation and decreasing the gap. The first and most important measure is to establish a knowledge strategy, policy and coordinating, firstly, to permanent refine of the introduced realms in this study making committee, or counsel and secondly to take necessary measures to decrease the gap and do the followings.

1. Identifying and prioritizing the supplement of the financial resources in the organization section with an approach tending toward vast and strategic surveys.

2. Designing, performing and stabilizing the road map of knowledge of Electricity Industry based on pedagogy, research and the techniques required in the Electricity Industry.

3. Evaluating the benefits of selling the technical knowledge.

4. Codifying, notifying and deploying the technical qualification service of the employed human resources, contracting companies and active counselors.

5. Identifying the targeted markets and facilitating the training, research and technological services.

6. Studying the grounds for common works and being present in the targeted markets and performing it.

7. Re-examining the topics of pedagogy and designing and running new training classes in the related fields.

8. Identifying, codifying and running training classes related to the standards of the Electricity Industry.

9. Holding conferences, periodical interviews with reporters, intellectuals and specialists of the Electricity Industry in order to keep the communication net, making it possible to talk about the problems and their solutions in the Electricity Industry.

10. Supporting the establishment and development of progress canons in the technology parks in case of the technologies of the Electricity Industry.

11. Increasing the privilege ration of the membership of the specialists in the knowledge communities in the rules of the job promotion.

12. Evaluating the job satisfaction and adopting strategies to increase the personnel's motivation and refining the social respect for the specialists

13. Deploying professional systems to enhance the performance level of the specialists.

14. Designing a procedure for the presence of the specialists of the organization at the decision making centers and carrying out it.

15. Optimal support from the commercialized products related to the Electricity Industry.

16. Evaluating the probability of the establishment and depositing local and international science and research centers in the Electricity Industry.

17. Designing a procedure for the presence of the related members of the educational boards in the board of the managers of the Electricity Industry companies.

18. Designing and creating a motivation system for researchers and inventors in order to make them eager to take part in the researches

19. Studying the development, transition and localization of the needed technologies.

20. Designing a process to put into evaluation permanently the requirements of pedagogies related to the new technologies and carrying out them.

21. Designing training classes in line with the contracts for localizing the new technologies.

22. Identifying the centers pioneer in the science and technology in the Electricity Industry and contracting with them.

23. Identifying and prioritizing the agents holding new technology training classes.

24. Designing the road map for the new key points in the Electricity Industry

25. Making use of the stabilizing reports about the changes in science and technology.

26. Evaluating the joint centers in training and research.

27. Studying, identifying, describing and carrying out research national and international joint projects. 
28. Development of using the capacities of the market of the carbon and the greenhouse gases in the way of making use of the new technologies and elevating the level of the environmental facet in the Electricity Industry.

29. Evaluating and ranking the active ones in the private sector in fields of training, research and technology and planning to give reference to this sector.

30. Updating and elevating the system for empowering the managers and also the management systems.

31. Preparing and depositing knowledge management systems in the Electricity Industry based on the knowledge strategy in the Electricity Industry.

32. Evaluating the companies' performance in depositing the knowledge management systems based on the knowledge strategy and ranking them.

33. Identifying the research projects in the related fields and supporting them.

34. Identifying and prioritizing the key technologies related to the Electricity Industry.

35. Identifying systems, pedagogies and the appropriate tools for the emergence of creativity and innovation

36. The pathology of the research and technology bank and looking for the ways to establish and reinforce banks.

37. Studying, identifying and founding legal techniques to give variety to the financial resources of the organization and related directives

38. Identifying and studying the mechanism necessary for elevating the moral and material place of the specialists

39. Performing the methods reinforcing the scientific and professional ability and capability of the experts and the specialists.

40. Identifying the strategies for increasing the job motivation and improving the social respect of the specialists.

41. Studying the methods for supporting the domestic production.

42. Identifying and applying the strategies of commercializing the findings of studies in the power industry.

43. Preparing the instruction of the way of cooperation with people-oriented organizations and research and science centers.

44. Qualitative and quantitative evaluation of regional research and science centers' potential from the technical-scientific dimension in the way of Electricity Industry's need.

45. Identifying the changes related to Electricity Industry and planning an appropriate pattern for applying them.

46. Preparing the research management system in the Electricity Industry.

47. Checking and planning them scientific enhancement of researchers (training, expertness, education, educational board...)

48. Establishment of the fund of supporting internal manufacturers of goods and tools of the Electricity Industry ( with requirement providing facilities, financial help, the expenses of inside and outside test and ...)

49. Establishing the networks of referential labs (for attracting regional tests).

\section{References:}

[1]. Abou-Zied; El-Sayed (2002), An Ontology-Based Approach to Interorganizational Knowledge Transfer, Journal of Global Information Technology Management, Vol 5,No 3

[2]. Asoh, D (2004), Business and Knowledge strategies: Alignment and performance impact analysis, PhD. Thesis, School of Information Science and Policy, University at Albany State University of New York.

[3]. Asoh, D., Belardo, B. and Neilson, R. (2002). "KM: Challenges and Opportunities for Government in the New Economy". Proceedings of the 3_th International Conference on System Science.

[4]. Barquin R and Clarke D.S. (2001). 'Knowledge Management in the Public Sector: A Survey'. E-Gov Knowledge Management Conference, Washington, D.C

[5]. Bierly, P and Daly, P (2002), 'Aligning Human Resource Management practices and knowledge strategies', The strategic management of intellectual capital and organizational knowledge, Oxford University Press, UK.

[6]. Bierly; Paul, Chakrabarti; Alok, (1996), Generic Knowledge Strategies in theU.S. Pharmaceutical Industry, Strategic Management Journal, Vol 17.

[7]. Boisot, H(2003)" Knowledge Assets" Electronic Journal of Knowledge Management. Vol. 3 Issue. 1 pp36-42

[8]. Bolisani E., Scarso E.,(2009)"Models and strategies for managing knowledge in networked

[9]. environments: The viewpoint of small business",ICSB World Conference International Council for Small Business, Seoul, South Korea, 21-24 June

[10]. Boyne, G.A (2002). "Public and Private Management: What's the Difference?"

[11]. Journal of Management Studies 39:1 January, pp. 97-122.

[12]. Cheng,Ching-Hsue \& Lin,Yin.(2002)"Evaluating the best mail battle tank using fuzzy decision theorywith linguistic criteria evaluation" , European Journal of Operational Research, vol.142, p.147

[13]. Choi, B \& Jong, AM (2005), 'An examination of KM strategies and the Market Value of the Firm: based on the Event study Methodology', in Proceedings of the 2nd International Conference on Knowledge Management in Asia Pacific (KMAP'05), 28-29 Nov, Wellington, New Zealand. 
[14]. Choi, B \& Lee, H (2002), 'Knowledge management strategy and its link to knowledge creation process', Expert systems with application, Vol. 23, No 3, pp. 173-187.

[15]. Civi; Emin (2000), Knowledge Management as a Competitive Asset: a Review, Marketing Intelligence \& Planning, Vol 18, No4

[16]. Cong, Xiaoming. and Pandya, Kaushik V. (2003). "Issues of Knowledge Management in the Public Sector", Electronic Journal of Knowledge Management. Vol. 1 Issue. 2 p21

[17]. Davenport, TH \& Prusak, L (2000), 'Working Knowledge, how organizations manage what they know', Harvard Business School Press, Boston, MA.

[18]. De Gooijer, J.(2008), " Designing a knowledge management framework"Journal of Knowledge Management, Vol. 14, No 24, pp. $303-310$

[19]. Earl. MJ (2001).Knowledge Management Strategies:Toward a taxonomy. Journal of Management Information Systems, 18(1), 215233

[20]. Fahey, L. (2006), "Putting knowledge into strategy", Presentation at the Ernst \& Young Managing the Knowledge of the Organization Conference, Phoenix.

[21]. GAO (2004).“Major Management Challenges and Programm Risks: A Government wide Perspective”. General Accounting Officer Report GAO-Vol.1 No21.

[22]. Hansen, M., Nohria, N., Tierney, T. (1999), "What's your strategy for Managing knowledge ? ", Harvard Business Review, Vol. 77 No.2, pp.106-116.

[23]. Holsapple, C.W. and Jones, K. (2006) "Knowledge Management Strategy Formation”, Encyclopedia of Knowledge Management, Idea Group, pp 419-428.

[24]. Jones, PH (2000), 'Knowledge strategy: Aligning knowledge programs to business strategy', Knowledge Management World 2000, Santa Clara, CA, September 12-15.

[25]. Keskin, H; Akgun, AE; Gunsel, A \& Imamoglu, SZ (2005),'The Relationship Between Adhocracy and Clan Cultures and Tacit Oriented KM Strategy', Journal of Transnational Management, Vol.10, Issue 3, pp. 39-53.

[26]. Kasten, J. (2007) "Knowledge strategy and its influence on knowledge Organization", Proceedings of the North American Symposium on Knowledge Organization. Vol 1

[27]. McAdam, R. and Reid, R. (2005). "A Comparison of Public and Private Sector Perceptions and Use of Knowledge Management". Journal of European Industrial Training Vol 19. No 1 pp. 317-329.

[28]. OECD (2004)."Knowledge Management: Learning-by-Comparing Experiencesfrom Private Firms and Public Organizations".Summary Record of the HighLevel Forum held in Copenhagen.8 -9 Feb.

[29]. Skyrme, DJ (2001), Capitalizing on knowledge: from e-business to k-business, Butterworth- Heinemann. Oxford, UK.pp111-135

[30]. Smith, H \& McKeen, J, (2003), 'Developing and Aligning a KM Strategy', Queen's Center for Knowledge-Based Enterprises, May, Ontario, Canada.pp 78-104

[31]. Snyman; Retha, Kruger; Cornelius J. (2004), The Interdependency between Strategic Management and Strategic Knowledge Management, Journal of Knowledge Management, Vol 8, No1.

[32]. Sveiby, K-E. (2001) “A knowledge-based theory of the firm to guide in strategy formulation", Journal of Intellectual Capital, Vol 11, No. 4, pp 344-358.

[33]. Wiig, K.M. (1997), "Knowledge Management: where did it come from and where will it go?", Expert System with Application, Vol. 13, Issue 1 , pp. 1-14

[34]. Zack, Michael H. (1999), Developing a knowledge Strategy, California Management Review, Vol 14, No 3.

[35]. Zack, Michael H.,(2002)The Strategic Management of Intellectual Capital and Organizational Knowledge: A Collection of Readings, Oxford University Press pp231-247 